\title{
A FIEDLER-TYPE THEOREM FOR THE DETERMINANT OF $J$-POSITIVE MATRICES
}

\section{NATÁlia BEBIANO AND Jõ̃o DA PROVIDÊNCIA}

Abstract. In this note we characterize the set of all possible values attained by the determinant of the sum of two $J$-positive matrices with prescribed spectra, under a natural compatibility condition.

Mathematics subject classification (2010): 46C20, 47A12.

Keywords and phrases: $J$-selfadjoint matrix, indefinite norm, determinant.

\section{REFERENCES}

[1] N. Bebiano, A. KovaceC And J. Da Providência, The validity of Marcus-de Oliveira Conjecture for essentially Hermitian matrices, Linear Algebra Appl. 197 (1994) 411-427.

[2] N. Bebiano, R. Lemos, J. DA Providência And G. SoARes, Further developments of Furuta inequality of indefinite type, Mathematical Inequalities and Applications, 13 (2010) 523-535.

[3] N. Bebiano, J. K. Merikoski and J. da Providência, On a conjecture of $G$. N. de Oliveira, Linear Multilinear Algebra, 20 (1987), 167-170.

[4] J. BognaR, Indefinite inner product spaces, Springer, 1974.

[5] S. W. Drury And B. Cload, On the determinantal conjecture of Marcus and de Oliveira, Linear Algebra Appl. 177: 105-109 (1992).

[6] S. W. DRURY, Essentially Hermitian matrices revisited, Electronic Journal of Linear Algebra, 15 (2006) 285-296.

[7] M. FiedLeR, The determinant of the sum of Hermitian matrices, Proc. Amer. Math. Soc. 30 27-31 (1971).

[8] C.-K. LI, Y.-T. Poon AND N.-S. SZE, Ranks and determinants of the sum of matrices from unitary orbits, Linear and Multilinear Algebra, 56 108-130 (2008).

[9] M. MARCus, Plucker relations and the numerical range, Indiana Univ. Math. J. 22:1137-1149, (1973).

[10] M. L. Menta, Matrix Theory, Sected Topics and Useful Results, Industan Publishing Corporation, New Delhi, 1971.

[11] H. Nakazato, N. Bebiano And J. DA PRovidÊNCia, $J$-orthostochastic matrices of size $3 \times 3$ and numerical ranges of Krein space operators, Linear Algebra Appl. 407 211-232 (2005).

[12] G. N. DE OliveIRA, Linear and Multilinear Algebra 12 153-154 (1982).

[13] M. ABRAmowitz AND I. A. STEgun (EDS), Handbook of Mathematical Functions with Formulas, Graphs, and Mathematical Tables, National Bureau of Standards, Applied Mathematics Series 55, 9th printing, Washington, 1970.

[14] W. BURNSIDE, A rapidly convergent series for $\log N$ !, Messenger Math., 46, 1 (1917), 157-159. 